\title{
MEASURING MALE INFERTILITY: EPIDEMIOLOGICAL ASPECTS
}

Fábio Firmbach Pasqualotto, Cristhiany Victor Locambo, Kelly Silveira Athayde and Sami Arap

PASQUALOTTO FF et al. - Measuring male infertility: epidemiological aspects. Rev. Hosp. Clín. Fac. Med. S. Paulo 58 (3): $173-178,2003$.

Evidence suggests that human semen quality may have been deteriorating in recent years. Most of the evidence is retrospective, based on analysis of data sets collected for other purposes. Measures of male infertility are needed if we want to monitor the biological capacity for males to reproduce over time or between different populations. We also need these measures in analytical epidemiology if we want to identify risk indicators, risk factors, or even causes of an impaired male fecundity - that is, the male component in the biological ability to reproduce.

The most direct evaluation of fecundity is to measure the time it takes to conceive. Since the time of conception may be missed in the case of an early abortion, time to get pregnant is often measured as the time it takes to obtain a conception that survives until a clinically recognized pregnancy or even a pregnancy that ends with a live born child occurs. A prolonged time required to produce pregnancy may therefore be due to a failure to conceive or a failure to maintain a pregnancy until clinical recognition. Studies that focus on quantitative changes in fecundity (that does not cause sterility) should in principle be possible in a pregnancy sample. The most important limitation in fertility studies is that the design requires equal persistency in trying to become pregnant and rather similar fertility desires and family planning methods in the groups to be compared. This design is probably achievable in exposure studies that make comparisons with reasonable comparable groups concerning social conditions and use of contraceptive methods.

\section{DESCRIPTORS: Infertility. Epidemiology. Semen. Sperm count. Testicle.}

A substantial body of evidence has accumulated in recent years suggesting that human semen quality may be deteriorating ${ }^{1-3}$. Unfortunately, the evidence remains inconclusive, with a number of publications showing clear evidence of a fall in sperm counts, and an equal number showing no evidence of change. Most of the evidence is retrospective, based on analysis of data sets collected for other purposes, and there is little data from outside Europe and North America. Numerous reports have recently focused on various aspects of adverse trends in male reproductive health, supporting a new concept that poor semen quality, testis cancer, undescended testis, and hypospadias are symptoms of one underlying entity, the testicular dysgenesis syndrome, which may be increasingly common due to adverse environmental influences ${ }^{4-8}$.

Measures of male infertility are needed if we want to monitor the biological capacity of males to reproduce

From the Urological Division, Hospital das Clínicas, Faculty of Medicine, University of São Paulo - São Paulo/SP, Brazil. Received for publication on February 06, 2002. over time or between different populations. We also need these measures in analytical epidemiology if we want to identify risk indicators, risk factors, or even causes of an impaired male fecundity - that is, the male component in the biological ability to reproduce. The debate concerning a possible decline in sperm values over time has clearly demonstrated our lack of proper instruments and data to be used in this research ${ }^{1-14}$.

The measures that have been used so far span from direct measures of reproduction to indirect surrogate measures based upon biomarkers ${ }^{15-17}$. In the following article, some of the meth- 
odological considerations associated with these biomarkers will be discussed.

\section{FERTILITY}

Fertility (the actual birth of live offspring in women of reproductive age) changes over time and differs among regions. Possible declining sperm quality and indications of deteriorating male reproductive health over the last 50 years have generated wide scientific and public interest. These trends could result from environmental influences on male fertility and gamete function. Some of the most striking data are from the DES story and the TCDD exposure at the Seveso disaster; they support the hypothesis that exogenous chemicals could act as endocrine disrupters and that these products could be disseminated in our environment ${ }^{18}$. However, other chemical and physical environmental factors can also directly disturb male reproductive function, as is the case for radiation exposure ${ }^{19}$. Correct epidemiological risk assessments for these alterations could serve as a basis for adequate prevention programs.

The major determinants for indications of deteriorating male reproductive health are probably related to social factors and access to safe contraceptive methods rather than reduced biological capacity to reproduce. Unfortunately, we do not know how to isolate the role of fecundity in these comparisons, and we do not expect the even rather profound declines in fertility, as reported by several European populations, reflect change in male fecundity. Measurements of fertility may on the other hand be a cheap and useful indication of male fecundity when used within the same population and within the same period. Studies on testicular cancer patients reveal a lower fertility for these men up to the time of diagnosis than for other men in the same age groups ${ }^{7,8,20}$. It is possible that this reduced fertility reflects differences in fecundity, although alternative explanations cannot be ruled out. Standardized fertility ratios have also been used in occupational epidemiology. Comparing the observed and expected number of live born children before, during, and after a given occupational exposure has been used to demonstrate the effect of dibromochloropropane (DBCP). ${ }^{21}$

Fertility as a measure of changes in fecundity over time and between countries, however, is not a good indication for male fecundity. In most affluent societies where both males and females work outside home, the desired family size tends to be small, and even couples with severely reduced fertility will often manage to produce the child they want. Therefore, factors such as birth control, sexual desire and ability, and male and female fecundity all contribute to the family size. Fecundity will decline over time as a result of these changes in population selection. If male fecundity is closely linked to hereditable factors, a decline in fecundity may be expected even after a few generations.

\section{TESTICULAR DYSGENESIS SYNDROME}

Several reports in the literature have suggested a possible decline in human semen quality during the last 50 to 60 years ${ }^{1-14}$. However, the decline in sperm counts was suspected to reflect changes in the policy of infertility treatment or a bias in selection of patients rather than a time-related biological phenomenon.

A systematic analysis of 61 studies was undertaken by Carlsen in 1992. It showed a significant decrease in sperm concentration (from 113 million/mL to 66 million/mL) and semen volume (from $3.4 \mathrm{~mL}$ to $2.75 \mathrm{~mL}$ ) over the period from 1938 to $1990^{10}$. These results have been discussed in the literature and have stimulated extensive research. A limitation of the study by Carlsen comes from the fact that there is a geographical heterogeneity of semen quality. This point has been taken into account in a new reanalysis of all available data concerning this problem published by Swan et al. concerning 101 studies published from 1934 to $1996^{14}$. Trends over time were estimated separately for each continent, which allows taking into account the confounding effect of the area of inclusion of the subjects. The average decline in sperm count was virtually unchanged from that reported previously by Carlsen et al. In North America, the slope was somewhat less than previously reported. The decline in Europe was even greater than previously reported, whereas the few studies from other continents showed no trend. These results are consistent with those of Carlsen et al. and indicate that, after controlling for abstinence time, age, percent of men with proven fertility, and specimen collection method, there has been a negative trend in sperm production in Europe and North America for the period from 1934 to1996. Over this period of time, the decrease is about $50 \%$.

The largest single study undertaken on this subject comes from the analysis of 1351 healthy men volunteering for sperm donation in the sperm bank of Paris. ${ }^{3}$ After taking into account all potential covariates, a yearly decrease of $2.6 \%$ in sperm concentration, $0.3 \%$ in percentage of motile sperm, and $0.7 \%$ in the percentage of morphologically normal spermatozoa were found.

When these observations are brought together with the increasing incidence of testicular cancer in all the countries in which it is measured, and with the reported increased incidence 
of cryptorchidism and of hypospadias, the existence of a single syndrome, the "testicular dysgenesis syndrome" (TDS), that would associate these 3 elements, seems likely. These anomalies (decreasing sperm production, testicular cancer, and male genital tract malformations) are not necessarily associated in the same individuals, but they are statistically linked to the population level; however, one study showed that low sperm concentration, poor spermatozoa motility, and a high proportion of morphologically abnormal spermatozoa were all associated with an increased risk of testicular cancer ${ }^{1,2}$.

It is well documented that rare genetic abnormalities that cause testicular dysgenesis (45X/46XY and androgen insensitivity) are associated with a high risk of testicular cancer, often in combination with undescended testis and hypospadias ${ }^{22}$.

\section{TIME TO PREGNANCY (TTP)}

The most direct evaluation of fecundity is to measure the time it takes to conceive. Since the time to conception may be missed in the case of an early abortion, TTP is often measured as the time it takes to produce a conception that survives until clinical recognized pregnancy or even a pregnancy that ends with a live born child $^{23-27}$. A prolonged TTP may therefore be due to a failure to conceive or a failure to maintain a pregnancy until a clinical recognition.

Demographers speak about fecundity as the probability of becoming pregnant within a given menstrual cycle. An expected fecundity is around 0.25 for producing a clinical recognized pregnancy, meaning that $25 \%$ of these couples will become pregnant the first cycle they try, and 3\% will not succeed within 12 cycles $^{27,28}$.

The main problems in TTP studies are related to getting proper measure- ments from the starting time of the planned pregnancy, and to getting repeated measurements over the TTP period. Measurements should perhaps start 3 months before the starting time for the male study to allow for the time of spermatogenesis. The data should at least include information on the frequency and timing of sexual intercourse, pregnancy planning, sexual desire and ability, and male or female fecundity.

Studies that focus on quantitative changes in fecundity (that do not cause sterility) should in principle be identifiable in a pregnancy sample. The most important limitation in fertility studies is that the design requires equal persistency in trying to become pregnant and rather similar fertility desires and family planning methods in the groups to be compared. This design is probably achievable in exposure studies that make comparisons with reasonably comparable groups concerning social conditions and use of contraceptive methods ${ }^{29,30}$. The alternative is to use surveys that include non-selected segments of the population or population segments that are only sampled according to their exposure status. These surveys should include information on important determinants of fecundity and the determinants of being exposed to unprotected intercourse.

We have limited information on TTP distribution over time, and the existing information is of poor quality $^{31-32}$. Given these limitations, we have no indication to support that we have much longer or shorter TTPs than what we had 30 to 40 years ago. Limitations in evaluating the TTP in pregnancy patients include the exclusion of fertile couples, differences in compliance rates, differential persistency in trying, and quality of recall. Limitations in evaluating TTP in the general population include low response rates, that studies may include both
TTP and time of unprotected intercourse, and that large sample sizes are required for meaningful results. The primary methodological limitations in the TTP studies include the use of contraceptive methods, infertility treatment, method of pregnancy testing, and lack of a standardized questionnaire. These are some of the problems related to using TTP for measuring a couple's fecundity and for isolating the male component.

Because of infertility treatment, the "natural TTP history" is usually not available for more than 1 to 2 years depending on how developed the country is is $^{33,34}$. The standard practice in data analysis is therefore to stop counting TTP after 12 months. Perhaps this practice should be implemented at 9 months for couples who have tried to become pregnant before. Consideration should also be given to modification of life-style habits based on previous pregnancy experience..$^{35}$ For exposures that may have a short term and reversible effect, this parameter may cause serious problems that are often not properly addressed in reproductive epidemiology.

For studies that have fecundity as the endpoint, semen may be an alternative surrogate measure. From an epidemiological point of view, there are 2 main related shortcomings; 1 is the unknown predictive value of most semen characteristics for fecundity, and the other is the difficulty in getting samples that are not too distorted by selection bias-related to non-responders. Many studies based on sperm samples rely upon populations with response rates below $50 \%$, or they are based on highly selected samples like those from semen donors or males seeking infertility treatment. The first group oversamples those with problems, and these forces of selection have most likely changed over time. Furthermore, studies indicate that males who volunteer for semen stud- 
ies oversample those with perceived fertility problems $\mathrm{s}^{4,5,36,37}$.

Other biomarkers, including inhibin B, that only require blood sampling are of interest. Blood may be available in large population studies and in biobanks stored over time. Unfortunately, we still do not know the predictive values of inhibin B levels concerning fecundity.

\section{CONCLUSIONS}

The last 10 to 20 years of methodological research indicate that we must deal with substantial problems if we want to monitor fecundity over time. The present technology is not appropriate for detecting more subtle changes and will probably result in misleading interpretations. The best approach is perhaps to carry out proper population surveys us- ing standardized questionnaires that record all time periods of unprotected sex within the last 5 years and that chronicle the social, behavioral, and disease settings needed to interpret the data.

There are good reasons to believe that important determinants of male fecundity operate early in life, perhaps even in fetal life. Studies that will permit a life-course approach should be performed ${ }^{5}$.

\section{RESUMO}

PASQUALOTTO FF e col. - Avaliando infertilidade masculina: aspectos epidemiológicos. Rev. Hosp. Clín. Fac. Med. S. Paulo 58(3):173-178, 2003.

Evidências nos últimos anos sugerem que a qualidade seminal humana talvez esteja deteriorando. Muitas evidências são retrospectivas, baseadas nas análises de dados coletados com outros propósitos. Aferições da infertilidade masculina são necessárias se quisermos monitorar a capacidade biológica para homens se reproduzirem com o passar do tempo ou entre populações diferentes. Nós igualmente necessitamos avaliar essas aferições em epidemiologia analítica se quisermos identificar indicadores de risco, fatores de risco ou mesmo a causa para piora da fecundidade masculina, o componente masculino da habilidade biológica para reprodução.

A mais direta avaliação da fecundidade é medir o tempo necessário para conceber. Uma vez que o tempo da gravidez pode não ser detectado quando de um aborto precoce, o tempo para engravidar é geralmente avaliado como o tempo necessário para obter gravidez que sobreviva até a detecção clínica da gravidez ou mesmo a gravidez que resulte no nascimento de uma criança. Um prolongado tempo para engravidar talvez decorra de algum problema inerente ao parto ou falha na manutenção da gravidez até a detecção clínica da mesma. Estudos que focalizam nas mudanças na fecundabilidade (sem causar esterilidade) deveriam a princípio ser identificados numa amostra de mulheres grávidas. A limitação mais importante é que tal desenho requer não apenas persistência em se tornar grávida, mas também métodos de planejamento familiar similar em grupos para serem comparados. Isto é provavelmente alcançado em estudos de exposição que fazem comparações com grupos comparáveis com relação à condição social e método contraceptivo.

DESCRITORES: Infertilidade. Epidemiologia. Sêmen. Concentração espermática. Testículo. 


\section{REFERENCES}

1. SKAKKEBAEK NE, RAJPERT-DE MEYTS E, MAIN KM Testicular dysgenesis syndrome: and increasingly common developmental disorder with environmental aspects. Hum Reprod 2001; 16: 972-978.

2. JORGENSEN N, ANDERSEN A-G, EUSTACH F et al. - Regional differences in semen quality in Europe. Hum Reprod 2001; 16: $1012-1019$.

3. AUGER J, KUTMANN JM, CZYGLIK F et al. - Decline in semen quality of fertile men during the last 20 years. New Engl J Med 1995; 332: 281-85.

4. BONDE JPE, HJOLLUND NHI, JENSEN TK et al. - A follow-up study of environmental and biologic determinants of fertility among 430 Danish first-pregnancy planners: design and methods. Reprod Toxicol 1998; 12: 19-27.

5. OLSEN J - Prenatal exposures and long-term health effects. Epidemiol Rev 2000; 22: 76-81

6. MOLLER H - Trends in incidence of testicular cancer and prostate cancer in Denmark. Hum Reprod 2001; 16: 1007-1011.

7. PASQUALOTTO FF, KOBAYASHi H, DAITCH JA et al. Detection of testicular cancer in men presenting with infertility [Abstract O-137]. In: Programs and abstracts from ASRM/ CFAS Conjoint Annual Meeting. Toronto, Canada: American Society for Reproductive Medicine and Canadian Fertility and Andrology Society 1999; 72: S-54.

8. PASQUALOTTO FF, AGARWAL A - Should we offer semen cryopreservation to men with testicular cancer? Cleve Clin J Med 2001; 68(2): 101-102.

9. BOSTOFTE E., SERUP J, REBBE H - Has the fertility of Danish men declined through the years in terms of semen quality? A comparison of semen qualities between 1952 and 1972. Int J Fertil 1993; 28: 91-5.

10. CARLSEN E, GIWERCMAN AJ, KEIDING $\mathrm{N}$ et al. - Evidence for decreasing quality of semen during past 50 years. BMJ 1992; 305: 609-13

11. SHARPE RM, SKAKKEBAEK NE - Are oestrogens involved in falling sperm counts and disorder of the male reproductive tract? Lancet 1993; 341: 1392-5.

12. OLSEN J - Is human fecundity declining — and does occupational exposures play a role in such a decline if it exists? Scand $\mathbf{J}$ Work Environ Health 1994; 20: 72-7.

13. SKAKKEBAEK NE, KEIDING $\mathrm{N}$ - Changes in semen and the testis. BMJ 1994; 309: 1316-7.

14. SWAN SH, ELKIN EP, FENSTER L et al. - The question of declining sperm density revisiting an analysis of 101 studies published 1934-1996. Environn Health Perspect 2000; 108: 961-966.

15. BONE JP, ERNST E - Sex hormones and semen quality in welders exposed to hexavalent chromium. Hum Exp Toxicol 1992; 11: $259-63$.
16. HJOLLUND NH, BONDE JP, JENSEN TK et al. - Semen quality and sex hormones with the reference to metal welding. Reprod Toxicol 1998; 12: 91-5.

17. KOLSTAD HA, BONDE JP, SPANO M et al. - Sperm chromatin structure and semen quality following occupational styrene exposure. Asclepius Scand J Environ Health 1999; 25: 70-3.

18. MOCARELLI P, GERTHOUX PM, FERRARI E et al. - Paternal concentrations of dioxin and sex ratio of offspring. Lancet 2000; 355: 1858-1863

19. COZZOLINO DJ, LAMB DJ - Are endocrine disruptors a cause of male reproductive defects? Contemp Urol 2000, 19: 6974 .

20. SAVAGE MO, LOWE DG - Gonadal neoplasia and abnormal sexual differentiation. Clin Endocrinol 1990; 32: 519-33.

21. LEVINE RJ, SYMONS MJ, BALOGH SA et al. - A method for monitoring the fertility of workers. Validation of the method among workers exposed to dibromochloropropane. J Occup Med 1981; 23: 183-8.

22. RAJPERT-DE MEYTS E, TOPPARI J, SKAKKEBAEK NE Testicular tumors with endocrine manifestations. In: DE GROOT LJ, JAMENSON JL - Endocrinology. $4^{\text {th }}$ ed. Philadelphia, Saunders, 2000. c. 175.

23. RACHOOTIN P, OLSEN J - Prevalence and socioeconomic correlates of subfecundity and spontaneous abortion in Denmark. Int J Epidemiol 1982; 11: 245-9.

24. RACHOOTIN P, OLSEN J - The risk of infertility and delayed conception associated with exposures in Danish workplace. $\mathbf{J}$ Occup Med 1983; 25: 394-402.

25. OLSEN J, RACHOOTIN P, SCHIODT AV - Tobacco use, alcohol consumption and infertility. Int J Epidemiol 1982; 12: 17984

26. BAIRD DD, WILCOX AJ, WEINBERG CR - Use of time to pregnancy to study environmental exposures. Am J Epidemiol 1986; 124: 470-80.

27. WEINBERG CR, BAIRD DD, WILCOX AJ - Source of bias in studies of time to pregnancy. Stat Med 1994; 13: 671-81.

28. JUUL S, KARMAUS W, OLSEN J - Regional differences in waiting time to pregnancy: pregnancy-based surveys from Denmark, France, Germany, Italy and Sweden. The European Infertility and Subfecundity Study Group. Hum Reprod 1999; 14: 12504 .

29. BASSO O, JUUL S, OLSEN J - Time to pregnancy as a correlate of fecundity: differential persistence in trying to become pregnant as a source of bias. Int J Epidemiol 2000; 29: 85661.

30. OLSEN J - On behalf of the IEA European Questionnaire Group. Epidemiology deserves better questionnaires. Int J Epidemiol 1998; 27: 935 
31. MOSHER WD, PRATT WF - Fecundity and infertility in the Unites States: incidence and trends. Fertil Steril 1991; 56: 192-3.

32. MOSHER WD, PRATT WF - Fecundity and infertility in the Unites States, 1965-88. Advance Data 1990; 192: 1-12.

33. OLSEN J, KÜPFERS-CHINNOW M et al. - Seeking medical help for subfecundity: a study based upon surveys in five European countries. Fertil Steril 1996; 1: 95-100.

34. OLSEN J, BASSO O, SPINELLI A et al. - The European Study Group on Infertility and Subfecundity. Correlates of care seeking for infertility treatment in Europe. Eur J Public Health 1998; 8: 15-20.
35. OLSEN $\mathbf{J}$ - Options in making use of a pregnancy history in planning and analyzing studies of reproductive failure. $\mathbf{J}$ Epidemiol Community Health 1994; 48: 171-4.

36. LARSEN SB, ABELL A, BONE JP - Selection bias in occupational sperm studies. Am J Epidemiol 1998; 147: 681-5.

37. BONDE JPE, ERNST E, JENSEN TK - Relation between semen quality and fertility: a population-based study of 430 firstpregnancy planners. Lancet 1998; 352: 1172-7. 